\title{
An update of the tsetse fly (Diptera: Glossinidae) distribution and African animal trypanosomosis prevalence in north-eastern KwaZulu-Natal, South Africa
}

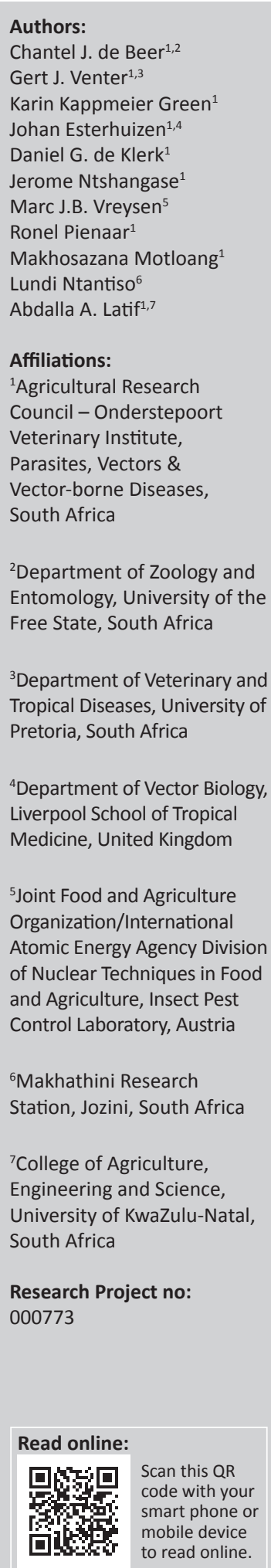

An unpredicted outbreak of African animal trypanosomosis or nagana in 1990 in north-eastern KwaZulu-Natal necessitated an emergency control programme, utilising the extensive cattledipping system in the area, as well as a reassessment of the tsetse and trypanosomosis problem in the province. Since 1990, sporadic blood sampling of cattle at the dip tanks in the naganainfested areas were undertaken to identify trypanosome species involved and to determine the infection prevalence in cattle. The distribution and species composition of the tsetse populations in the area were also investigated. From November 2005 to November 2007 selected dip tanks were surveyed for trypanosome infection prevalence. During April 2005 to August 2009 the distribution and abundance of tsetse populations were assessed with odour-baited $\mathrm{H}$ traps. The tsetse and trypanosome distribution maps were updated and potential correlations between tsetse apparent densities (ADs) and the prevalence of trypanosomosis were assessed. Glossina brevipalpis Newstead and Glossina austeni Newstead were recorded in locations where they have not previously been collected. No significant correlation between tsetse relative abundance and nagana prevalence was found, which indicated complex interactions between tsetse fly presence and disease prevalence. This was epitomised by data that indicated that despite large differences in the ADs of G. austeni and G. brevipalpis, trypanosome infection prevalence was similar in all three districts in the area. This study clearly indicated that both tsetse species play significant roles in trypanosome transmission and that it will be essential that any control strategy, which aims at sustainable management of the disease, should target both species.

\section{Introduction}

The discovery that Trypanosoma brucei Plimmer \& Bradford was the cause of African animal trypanosomosis (AAT), also known as nagana, can be dated back to the 1880s when it was recorded for the first time in north-eastern KwaZulu-Natal (formerly known as Zululand), South Africa (Bagnall 1993; Bruce 1895; Steverding 2008). In 1895, Sir David Bruce stated that game animals were the reservoir hosts of the causative trypanosome species and that these protozoan parasites were transmitted between their mammalian hosts by tsetse flies (Diptera: Glossinidae) (Bruce 1895). Four species of tsetse, that is, Glossina morsitans morsitans Westwood, Glossina pallidipes Austen, Glossina brevipalpis Newstead and Glossina austeni Newstead have been recorded in South Africa. G. m. morsitans was the only species that was encountered in the most northern parts of the country (this included the Kruger National Park and parts of the Limpopo and Mpumalanga provinces), bordering onto Zimbabwe in the north and Mozambique in the east (Fuller 1923). In 1897 after a large reduction of cattle and wildlife during the rinderpest epizootic of 1896-1897, G. m. morsitans completely disappeared from South Africa (Fuller 1923). The other three species of tsetse, that is, G. pallidipes, G. brevipalpis and G. austeni, remained present in the former Zululand in the north-eastern part of KwaZulu-Natal Province (Fuller 1923). Glossina pallidipes was the predominant species in north-eastern KwaZulu-Natal, and based on its abundance it was considered the most important vector of AAT at that time. G. brevipalpis and G. austeni, which were restricted to areas with mostly dense vegetation, were not considered as important vectors of AAT. The sheer abundance of G. pallidipes was illustrated by large numbers of flies being trapped on certain occasions, that is, in 1932, 2 million flies were collected within a

Corresponding author: Chantel de Beer, debeerc@arc.agric.za

Dates: Received: 09 Feb. 2016|Accepted: 11 Mar. 2016|Published: 09 June 2016

How to cite this article: De Beer, C.J., Venter, G.J., Kappmeier Green, K., Esterhuizen, J., De Klerk, D.G., Ntshangase, J. et al., 2016, 'An update of the tsetse fly (Diptera: Glossinidae) distribution and African animal trypanosomosis prevalence in north-eastern KwaZuluNatal, South Africa', Onderstepoort Journal of Veterinary Research 83(1), a1172. http://dx.doi.org/10.4102/ojvr.v83i1.1172

Copyright: ๑ 2016. The Authors. Licensee: AOSIS. This work is licensed under the Creative Commons Attribution License. 
month after deployment of 1000 Harris traps and nearly 8 million flies over that entire year (Harris 1932).

The presence of these large numbers of tsetse flies in northeastern KwaZulu-Natal resulted in severe outbreaks of nagana between 1942 and 1946 (Du Toit 1954). A campaign that was largely reliant on newly developed synthetic insecticides such as DDT (1,1,1-trichloro-2,2-di (4-chlorophenyl)ethane) and $\mathrm{HCH}$ (hexachlorobenzene) was launched between 1945 and 1952 to eradicate G. pallidipes. These chemicals were extensively used as part of residual aerial spraying campaigns that were aimed at creating a zone free of G. pallidipes in Zululand (Du Toit 1954). Surveys in 1953 failed to detect any G. pallidipes and it was concluded that this species was eradicated from Zululand (Du Toit 1954). The programme was very successful because it integrated several control tactics (aerial spraying, trapping and bush clearing). Furthermore, it was sustainable as the entire G. pallidipes population was targeted and KwaZulu-Natal is today still free of this species. This was one of the first tsetse fly control programmes that was implemented following Area-Wide Integrated Pest Management (AW-IPM) principles (Klassen 2005; Vreysen, Robinson \& Hendrichs 2007).

An additional benefit from this campaign was the apparent removal of G. brevipalpis from the Hluhluwe-iMfolozi Park (Du Toit 1954). In areas where G. brevipalpis and G. austeni were found in the absence of G. pallidipes, no control efforts were implemented against these species, and consequently, these two species remained present in Zululand (Kappmeier, Nevill \& Bagnall 1998).

From 1955 onwards, only sporadic cases of nagana were recorded in Zululand (Bagnall 1993, 1994). However, in 1990, a severe outbreak of nagana once again occurred in northeastern KwaZulu-Natal. Cattle mortalities during this outbreak were exacerbated by the co-occurrence of a severe drought (Emslie 2005; Kappmeier et al. 1998). Emergency control measures were implemented that relied on the extensive dipping network that was mainly used for tick control in KwaZulu-Natal (Kappmeier et al. 1998). As part of the control measures, the active ingredient of the acaricide dipping product was changed from amitraz to the pyrethroid cyhalothrin for a period of 2 years (Bagnall 1993). Whereas the pyrethroid cyhalothrin is very effective for controlling both ticks and tsetse flies (Bagnall 1993), the efficacy of amitraz is limited to ticks and is considered less effective against dipteran flies (Hall \& Fischer 1984). The adopted cattle-dipping regime in combination with animal treatments using trypanocidal drugs brought the disease outbreak under control (Kappmeier et al. 1998).

The 1990 outbreak illustrated that nagana had remained a serious debilitating problem in KwaZulu-Natal, with mixed infections of Trypanosoma congolense Broden and Trypanosoma vivax Ziemann (Bagnall 1993). A survey to determine the prevalence of Trypanosoma species in 1994 indicated the highest trypanosomosis prevalence in the Ubombo district of KwaZulu-Natal, while the lowest prevalence was found to be in the Hlabisa district, which surrounds the HluhlweiMfolozi Park (De Waal et al. 1998). Periodic screening of cattle in the tsetse-infested area indicated that T. congolense was the dominant species (Mamabolo et al. 2009; Motloang et al. 2012; Van den Bossche et al. 2006), T. vivax being present to a lesser extent (Mamabolo et al. 2009; Motloang et al. 2014). Recently Trypanosoma theileri (Laveran) and T. brucei were detected based on the alignment of 18S rRNA gene sequences which were comparable with trypanosome sequences available at the National Centre for Biotechnology Information (NCBI) (Taioe 2014). Two sub-genotypes of Trypanosoma congolense, the savannah and kilifi were identified with PCR (Mamabolo et al. 2009). Mixed infections of these two sub-genotypes were also observed (Gillingwater, Mamabolo \& Majiwa 2010). These surveys showed that trypanosome infections in cattle at dip tanks close to the Hluhluwe-iMfolozi Park were higher than at dip tanks further away from this game reserve (Motloang et al. 2014; Ntantiso et al. 2014; Van den Bossche et al. 2006).

Long-term management of nagana by dipping and/or curative treatment of infected cattle with trypanocidal drugs is neither cost effective nor sustainable (Bagnall 1994; Shaw 2009), and it became evident that a long-term solution to the nagana problem in South Africa could only be attained if vector control was to be included. Initial surveys showed that G. brevipalpis and G. austeni were still the only species present in KwaZulu-Natal (Kappmeier Green 2002).

Between 1993 and 1999, extensive tsetse fly surveys were conducted in an area of approximately $12000 \mathrm{~km}^{2}$ using odour-bated sticky XT traps (cross-shaped targets) to assess the distribution of each species (Figure 1a, b) (Kappmeier \& Nevill 1999a, Kappmeier Green \& Venter 2007). The survey indicated that G. brevipalpis was present in southern and northern bands, commonly associated with game reserves and other protected areas. The distribution of G. austeni was continuous from south to north and did not extend as far west as that of G. brevipalpis. G. austeni also was very common in communal farming areas (Kappmeier Green 2002). The 1993-1999 survey did not establish the southernmost distribution limit of G. brevipalpis and G. austeni, as the sampling frame was only designed to determine broad distribution limits. It was, however, suggested that the southernmost limit of the tsetse fly distribution in South Africa, and therefore Africa, could roughly be regarded as the southernmost extent of the Umfolozi River (Kappmeier Green 2002). The 1993-1999 survey also showed that G. brevipalpis and to a lesser extent G. austeni were present close to the coastal areas apparently not sampled in the 1950s (Du Toit 1954).

The entomological sampling data obtained from 1993 to 1999 (Kappmeier Green 2002) as well as environmental and climatic variables were used to develop a probability of presence model for these two species (Hendrickx 2002; 
Hendrickx et al. 2003). The model predicted a broader geographical distribution range for both G. brevipalpis and G. austeni than what was indicated by the survey data; however, Hendrickx et al. (2003) suggested that the model overestimated tsetse fly distribution.

Knowledge on the accurate distribution of the target insect, as well as the interaction of the insect with the causative agent it transmits, is vital for the successful implementation of any proposed control campaign and will directly affect its outcome, sustainability and cost (Shaw 2009; Vreysen et al. 2007). Additional ongoing efforts to generate continental as well as national Atlas of tsetse and AAT (Cecchi et al. 2014, 2015) will be benefited from continuously updated data sets.

The development of an improved trap for G. brevipalpis and G. austeni (Kappmeier 2000) and enhanced artificial odour system for G. brevipalpis (Kappmeier \& Nevill 1999a) allowed a more effective sampling of both species in South Africa. Subsequently, as a starting point, the prediction model of Hendrickx (2002) was validated through selective trapping in the area.

From 2005 to 2009, researchers at the Agricultural Research Council-Onderstepoort Veterinary Institute (ARC-OVI) carried out various studies. These included a transect study, based on the results of the distribution survey and prediction model, to determine the distribution of G. austeni to the west of the Hluhluwe Dam (Esterhuizen, Kappmeier \& Nevill unpublished data) and to assess fly presence and densities at dip tanks (Gillingwater et al. 2010; Mamabolo et al. 2009; Motloang et al. 2012; Ntantiso et al. 2014). In addition, tsetse population genetics (Koekemoer et al, unpublished data) and morphometric studies (De Beer et al. unpublished data) were conducted to assess the level of gene flow between the tsetse populations in KwaZulu-Natal and those in southern Mozambique and Swaziland.

The present paper collates the data of these different studies to update the existing maps on the distribution of tsetse flies and trypanosomosis in north-eastern KwaZulu-Natal. Correlation between tsetse apparent densities (ADs) and infection prevalence of the disease in livestock were also investigated.

\section{Materials and methods Study area}

The tsetse-infested area $\left( \pm 16000 \mathrm{~km}^{2}\right)$ in South Africa is confined to the north-eastern part of KwaZulu-Natal Province. The area stretches roughly from the Umfolozi River $(-28.5204,32.3123)$ in the south to the border of Mozambique $(-26.8692,32.8342)$ in the north, and from the Indian Ocean coast in the east up to the west of the Hluhluwe-iMfolozi Park (-28.33416, 31.691222) (Kappmeier Green 2002). Although some commercial cattle farms are present, it is predominantly a subsistence cattle-farming area with numerous communal farms that are interspersed with a number of protected areas.

The protected areas consist of provincial and private game parks and reserves. The area surrounding the extensive fresh water lake system, iSimangaliso Wetland Park, is a proclaimed world heritage site. These areas not only contain a wide variety of game animals, such as birds, rodents and smaller primates, but also large numbers of bigger mammals that are potential hosts for tsetse. The target area contains a number of state forests, mostly pine and eucalyptus plantations, and commercial sugarcane farms.

The climate is subtropical with average minimum temperatures ranging from $10.52{ }^{\circ} \mathrm{C} \pm 1.26{ }^{\circ} \mathrm{C}$ in July (winter) to $21.71{ }^{\circ} \mathrm{C} \pm 0.67{ }^{\circ} \mathrm{C}$ in January (summer). The average maximum temperature ranges from $24.65^{\circ} \mathrm{C} \pm 0.77{ }^{\circ} \mathrm{C}$ in July to $30.86{ }^{\circ} \mathrm{C} \pm 1.38{ }^{\circ} \mathrm{C}$ in January. The average minimum relative humidity ranges from $39.92 \% \pm 8.23 \%$ in July to $62.04 \% \pm 6.39 \%$ in October, whereas the average maximum relative humidity ranges from $92.23 \% \pm 3.73 \%$ in June to $94.94 \% \pm 3.13 \%$ in February. The area receives an average maximum of $132.92 \mathrm{~mm} \pm 92.95 \mathrm{~mm}$ of rain in January, and most of the precipitation is received in the hot season from October to March. However, it can also rain in the cold dry season from April to September with a minimum average $9.27 \mathrm{~mm} \pm 9.68 \mathrm{~mm}$ of rain in July. On average, more rain is received in the coastal area as compared with the interior.

\section{Tsetse fly sampling}

Tsetse fly collections were made at 18 sites located in four magisterial districts: Ingwavuma, Ubombo, Hlabisa and the northern part of Enseleni (Table 1; Figure 1a, b). A total of 77 odour-baited H traps (Kappmeier 2000; Kappmeier \& Nevill 1999b) were deployed at these 18 sites from April 2005 to April 2009. The number of trap days ranged from 723 at Ocilwane (northern Enseleni) to 1661 at False Bay Park (eastern Hlabisa district). The traps were baited with artificial odour baits to enhance trapping of G. brevipalpis (Kappmeier \& Nevill 1999a). These consisted of 1-octen-3-ol and 4-methylphenol at a ratio of 1:8 that were released at $4.4 \mathrm{mg} / \mathrm{h}$ and $7.6 \mathrm{mg} / \mathrm{h}$, respectively. The chemicals were dispensed from seven heat-sealed sachets $\left(7 \mathrm{~cm}{ }^{\prime} 9 \mathrm{~cm}\right)$ made from low-density polyethylene sleeves (wall thickness $150 \mu \mathrm{m}$ ) placed near the entrance of the trap. A $300 \mathrm{~mL}$ glass bottle that dispensed acetone through a $6-\mathrm{mm}$ hole in the lid at a rate of $c a .350 \mathrm{mg} / \mathrm{h}$ was placed next to the trap (Esterhuizen 2007; Kappmeier Green 2002). Flies were collected in a $20 \%$ ethanol solution to which Savlon ${ }^{\circledR}$ (Johnson \& Johnson, Pharmedica Laboratories [Pty] Ltd. Rattray Road, East London, South Africa) $(0.4 \mathrm{~mL} / \mathrm{L})$ and formalin $(0.4 \mathrm{~mL} / \mathrm{L})$ had been added to preserve the sampled flies as well as to protect them from ant and spider predation. Traps were emptied and serviced every 14 days. The number of each species of tsetse fly collected over this period was counted, and results for each species expressed as $\mathrm{AD}$, that is, the number of flies per trap per day. 
TABLE 1: Tsetse H trap catches from April 2005 to August 2009 in the north-eastern KwaZulu-Natal.

\begin{tabular}{|c|c|c|c|c|c|c|c|c|c|c|}
\hline \multirow{2}{*}{$\begin{array}{l}\text { Magisterial } \\
\text { districts }\end{array}$} & \multirow{2}{*}{$\begin{array}{c}\text { Numbers on } \\
\text { map }\end{array}$} & \multirow{2}{*}{$\begin{array}{l}\text { Tsetse sample } \\
\text { site }\end{array}$} & \multirow{2}{*}{$\begin{array}{l}\text { Number of } \\
\text { traps }\end{array}$} & \multirow[t]{2}{*}{ Start date } & \multirow[t]{2}{*}{ End date } & \multirow{2}{*}{$\begin{array}{l}\text { Total number } \\
\text { of trap days } \dagger\end{array}$} & \multicolumn{2}{|c|}{ Glossina brevipalpis } & \multicolumn{2}{|c|}{ Glossina austeni } \\
\hline & & & & & & & Collected & $\begin{array}{c}\text { Apparent } \\
\text { density }\end{array}$ & Collected & $\begin{array}{c}\text { Apparent } \\
\text { density }\end{array}$ \\
\hline \multirow[t]{5}{*}{ Ingwavuma } & 1 & Ndumu & 1 & $14-06-2006$ & $26-08-2009$ & 1169 & 6358 & 5.44 & 210 & 0.18 \\
\hline & 2 & Tembe & 4 & $14-06-2006$ & $26-08-2009$ & 4606 & 1529 & 0.33 & 135 & 0.03 \\
\hline & 3 & Pelani & 1 & $14-06-2006$ & $26-08-2009$ & 1169 & 11 & 0.01 & 0 & 0.00 \\
\hline & 4 & Kosi bay & 2 & $19-04-2006$ & $26-08-2009$ & 2262 & 444 & 0.20 & 1 & $<0.01$ \\
\hline & Total/district & - & 8 & $14-06-2006$ & $26-08-2009$ & 9206 & 8342 & 0.91 & 346 & 0.04 \\
\hline \multirow[t]{6}{*}{ Ubombo } & 5 & Tshongwe & 2 & $04-07-2006$ & $25-08-2009$ & 2275 & 0 & 0.00 & 7 & $<0.01$ \\
\hline & 6 & Mbazwana & 2 & $14-06-2006$ & $11-08-2009$ & 1750 & 0 & 0.00 & 263 & 0.15 \\
\hline & 7 & Lower Mkhuze & 3 & $14-06-2006$ & $25-08-2009$ & 3504 & 204 & 0.06 & 2022 & 0.58 \\
\hline & 8 & Mkhuze & 2 & $25-10-2006$ & $21-08-2009$ & 2062 & 1 & $<0.01$ & 23 & 0.01 \\
\hline & 9 & Phinda & 4 & $04-07-2006$ & $25-08-2009$ & 4550 & 261 & 0.06 & 2284 & 0.50 \\
\hline & Total/district & - & 13 & $14-06-2005$ & $25-08-2009$ & 14141 & 466 & 0.03 & 4599 & 0.33 \\
\hline \multirow[t]{9}{*}{ Hlabisa } & 10 & Kuleni & 3 & 01-01-2006 & $21-08-2009$ & 3984 & 697 & 0.17 & 856 & 0.21 \\
\hline & 11 & False Bay Park & 4 & 01-04-2005 & $18-08-2009$ & 6400 & 9894 & 1.55 & 3849 & 0.60 \\
\hline & 12 & Ekuphinidisweni & 6 & 01-05-2006 & 23-08-2009 & 5371 & 8529 & 1.59 & 0 & 0.00 \\
\hline & 13 & $\begin{array}{l}\text { Hluhluwe- } \\
\text { iMfolozi Park }\end{array}$ & 15 & 01-11-2005 & $19-08-2009$ & 11201 & 120313 & 10.74 & 277 & 0.02 \\
\hline & 14 & Mvutshini & 12 & 01-05-2005 & $18-08-2009$ & 15239 & 32451 & 2.13 & 65 & $<0.01$ \\
\hline & 15 & Hlambanyathi & 1 & 01-03-2006 & $31-08-2009$ & 1279 & 28 & 0.02 & 1 & $<0.01$ \\
\hline & 16 & Boomerang & 6 & 01-04-2005 & 03-08-2009 & 8199 & 11627 & 1.42 & 6424 & 0.78 \\
\hline & 17 & St Lucia & 3 & $23-10-2006$ & 21-08-2009 & 3099 & 22470 & 7.25 & 680 & 0.22 \\
\hline & Total/district & - & 50 & 01-04-2005 & $31-08-2009$ & 54772 & 206009 & 3.76 & 12152 & 0.22 \\
\hline \multirow[t]{2}{*}{ Enseleni } & 18 & Ocilwane & 6 & 01-11-2007 & $24-08-2009$ & 3882 & 1632 & 0.42 & 0 & 0.00 \\
\hline & Total/district & - & 6 & 01-11-2007 & $24-08-2009$ & 3882 & 1632 & 0.42 & 0 & 0.00 \\
\hline Total/study area & - & - & 77 & 01-04-2005 & $31-08-2009$ & 82001 & 216449 & 2.64 & 17097 & 0.21 \\
\hline
\end{tabular}

$\dagger$, Sum of collection days of all traps per site.

\section{Trypanosomosis survey}

A large number of communal dip tanks, constructed, maintained and operated by the Provincial Department of Veterinary Services, are routinely used for tick control and are homogeneously distributed throughout the tsetseinfested area. The tick control policy, as dictated by the Department of Veterinary Services, consists of weekly dipping of cattle in the summer and fortnightly dipping during the winter. Cattle in the communal farming areas as well as on the commercial farm Boomerang roam around freely. The trypanosome infection prevalence in cattle was determined at 27 dip tanks from November 2005 to November 2007 (Figure 1c). All animals that congregated at a particular dip tank were considered as one herd as they grazed together and were managed using the same animal husbandry practice (Emslie 2005; Ntantiso et al. 2014). Herd size was very variable and ranged from 13 to 6411 animals, and the number of cattle owners at each dip dank was likewise very variable and ranged between 5 and 296. Cattle were screened on the day they were scheduled for routine dipping. These herds were divided into groups of 30 to 40 cattle, and 2 to 3 animals in each group were randomly sampled. Table 2 lists the number of cattle sampled at each dip tank.

Blood was collected from the tail or jugular vein of adult animals using 10-mL vacutainer tubes containing the anticoagulant EDTA (BD Vacutainer ${ }^{\circledR}$; BD, Plymouth, United Kingdom) (Ntantiso et al. 2014). The blood was transferred to micro-haematocrit centrifuge capillary tubes (MarienfeldSuperior, Lauda- Königshofen, Germany) that were sealed with Cristaseal (Hawksley) and centrifuged in a haematocrit centrifuge for $5 \mathrm{~min}$ at $9000 \mathrm{rpm}$. The buffy coat of each specimen was extruded onto a microscope slide, covered with a cover slip and examined for motile trypanosomes under a compound microscope using a 40-times magnification (Paris, Murray \& McOdimba 1982). The trypanosomosis infection prevalence at each dip tank was expressed as the number of cattle that had a positive identification of trypanosomes in their buffy coat as a proportion of the number of cattle screened.

\section{Data analysis}

All data were analysed using the statistical software GraphPad Instat (version 3.00, 2003). Tsetse relative abundance was expressed as the AD of each species, that is, the number of flies collected per trap per day. For comparison of the relative abundance of G. brevipalpis and G. austeni populations, a paired test was used to differentiate between mean tsetse fly AD. The data were not normally distributed and the nonparametric Wilcoxon matched-pairs test was used. To evaluate the $\mathrm{AD}$ of each tsetse species per district, a one-way analysis of variance (ANOVA) was used to differentiate between the mean tsetse fly AD. The data were not normally distributed, thus a non-parametric method (Kruskal-Wallis test) was used. Additionally, Dunn's multiple comparison tests were used if the $p$ value $<0.05$. Proportional differences in trypanosome infection prevalence were determined with chisquare $\left(\chi^{2}\right)$ analysis with the Yate's continuity correction. Linear regression analysis was carried out on trypanosome infection prevalence and tsetse fly $\mathrm{AD}$, as well as infection prevalence and distances from game reserves. All statistical tests were done at the $5 \%$ significance level. 
TABLE 2: Trypanosome infection rates as determined by buffy coat examination of live trypanosomes collected from cattle at dip tanks from November 2005 to November 2007 in the north-eastern KwaZulu-Natal.

\begin{tabular}{|c|c|c|c|c|c|c|c|}
\hline \multirow[t]{2}{*}{ Magisterial districts } & \multirow{2}{*}{$\begin{array}{l}\text { Numbers } \\
\text { on map }\end{array}$} & \multirow[t]{2}{*}{ Dip tank } & \multirow{2}{*}{$\begin{array}{c}\text { Dip tank } \\
\text { sample date }\end{array}$} & \multirow{2}{*}{$\begin{array}{l}\text { Distance from game } \\
\text { park (km) }\end{array}$} & \multicolumn{2}{|c|}{ Buffy coat examination } & \multirow{2}{*}{$\begin{array}{c}\text { Trypanosome } \\
\text { infection prevalence }\end{array}$} \\
\hline & & & & & Positive & Negative & \\
\hline \multirow[t]{11}{*}{ Ingwavuma } & 19 & Ekuhlehleni & $25-05-2007$ & 11.6 & 1 & 49 & 0.02 \\
\hline & 20 & Khume & 01-06-2007 & 9.4 & 0 & 30 & 0.00 \\
\hline & 21 & Ndunot & $30-05-2007$ & 3.4 & 4 & 39 & 0.09 \\
\hline & 22 & Manzibomvu† & 05-09-2007 & 0.3 & 18 & 32 & 0.36 \\
\hline & 23 & Nhlanjwana† & $31-05-2007$ & 2.6 & 11 & 31 & 0.26 \\
\hline & 24 & Thengani & $17-05-2007$ & 2.1 & 4 & 35 & 0.10 \\
\hline & 25 & Ntabayengwe & $29-05-2007$ & 26.9 & 0 & 38 & 0.00 \\
\hline & 26 & Ngwenyambili† & $14-07-2006$ & 7.5 & 11 & 21 & 0.34 \\
\hline & 27 & Phelendaba† & $15-05-2007$ & 8.2 & 7 & 31 & 0.18 \\
\hline & 28 & Pongola $\dagger$ & $06-08-2007$ & 3.3 & 0 & 30 & 0.00 \\
\hline & Total/district & - & - & - & 56 & 336 & 0.14 \\
\hline \multirow[t]{8}{*}{ Ubombo } & 29 & Makhathini & 06-07-2007 & 20.2 & 0 & 32 & 0.00 \\
\hline & 30 & Mseleni† & $05-08-2007$ & 1.9 & 22 & 24 & 0.48 \\
\hline & 31 & Mpini & 05-11-2007 & 2 & 1 & 41 & 0.02 \\
\hline & 32 & Mkhumbikazare $\dagger$ & 05-10-2007 & 7 & 18 & 31 & 0.37 \\
\hline & 33 & Mbazwana† & 05-07-2007 & 4.3 & 4 & 34 & 0.11 \\
\hline & 34 & Zineshe† & $06-04-2007$ & 2.2 & 9 & 33 & 0.21 \\
\hline & 35 & Nibela† & 27-01-2007 & 3 & 3 & 30 & 0.09 \\
\hline & Total/district & - & - & - & 57 & 225 & 0.20 \\
\hline \multirow[t]{8}{*}{ Hlabisa } & 36 & Khipha & 23-11-2006 & 7.3 & 2 & 34 & 0.06 \\
\hline & 37 & Nthwati & $15-02-2006$ & 6 & 1 & 38 & 0.03 \\
\hline & 38 & Ekuphindisweni† & $25-10-2006$ & 3 & 10 & 17 & 0.37 \\
\hline & 39 & Mvutshini† & 21-05-2007 & 3 & 7 & 27 & 0.21 \\
\hline & 40 & Qakweni† & $15-08-2006$ & 7.4 & 8 & 83 & 0.09 \\
\hline & 41 & Mahlambanyati† & 30-11-2005 & 9.6 & 5 & 45 & 0.10 \\
\hline & 42 & Boomerang $\dagger$ & $18-08-2006$ & 9.5 & 24 & 30 & 0.44 \\
\hline & Total/district & - & - & - & 57 & 274 & 0.17 \\
\hline \multirow[t]{2}{*}{ Enseleni } & 43 & Ocilwane $\dagger$ & 09-07-2007 & 4.3 & 1 & 28 & 0.03 \\
\hline & Total/district & - & - & - & 1 & 28 & 0.03 \\
\hline Total/study area & - & - & - & - & 171 & 863 & 0.17 \\
\hline
\end{tabular}

$\dagger$, Dip tanks used in trypanosome infection tsetse regression analysis.

Maps were developed in ArcGIS Desktop 10.1 (ESRI, 2011). For the trypanosome infection prevalence, an inverse distance weighted interpolation method was used with a power 2 function and a variable search radius setting at 10 points.

\section{Results}

\section{Tsetse distribution and abundance}

A total of $77 \mathrm{H}$ traps were deployed at 18 sites located in four magisterial districts, that is, Ingwavuma, Ubombo, Hlabisa and Enseleni (Table 1; Figure 1a, b). These traps collected a total of 216449 G. brevipalpis ( $\mathrm{AD}=2.64$ flies/trap/day) and 17097 G. austeni $(\mathrm{AD}=0.21 \mathrm{flies} /$ trap/day $)$ between 01 April 2005 and 31 August 2009 (Table 1; Figure 1a, b).

While both tsetse species were collected in the three northerly districts, only G. brevipalpis was trapped (with six H traps) at Ocilwane in the northern part of the Enseleni district in the south (Table 1; Figure 1a). The overall AD of G. brevipalpis (2.64 flies/trap/day) was significantly higher $(p<0.001)$ than that of G. austeni (0.21 flies/trap/day). This might, however, be an artefact resulting from the intrinsic biases of the trapping system. Comparison of the ADs in the three northerly districts indicated that the AD of G. brevipalpis was significantly higher than that of G. austeni in the Ingwavuma $(p=0.008)$ and Hlabisa $(p<0.001)$ districts (Table 1; Figure 1a, b).
The AD of G. brevipalpis (0.03 flies/trap/day) in the Ubombo district was significantly lower than that of G. austeni (0.33 flies/trap/day) $(p<0.002)$ (Table 1$)$.

Glossina brevipalpis was most abundant in the Hlabisa district (3.76 flies/trap/day), and the AD was significantly higher $(p<0.001)$ than that in the Ubombo district $(0.03$ flies/trap/ day); an area where previously no G. brevipalpis were collected (Kappmeier Green 2002) (Table 1; Figure 1a).

Significantly higher numbers ( $p=0.025)$ of $G$. austeni $(\mathrm{AD}=0.33$ flies/trap/day) were collected in the Ubombo district as compared with the Hlabisa (0.02 flies/trap/day) and the Ingwavuma districts (0.04 flies/trap/day) (Table 1$)$. No G. austeni was trapped at Ocilwane in the Enseleni district (Table 1; Figure $1 \mathrm{~b}$ ). These trapping data indicated that the Monzi forest in the Hlabisa district maintained the most southerly distribution of G. austeni in KwaZulu-Natal (and Africa).

The greatest variations in ADs among sites within the same district (Table 1) were observed in the Hlabisa district for both G. brevipalpis $(p<0.001)$ and G. austeni $(p<0.001)$. The AD of G. brevipalpis in the Hluhluwe-iMfolozi Park (10.74 flies/trap/day) was significantly higher than that observed at Kuleni (0.17 flies/trap/day). There were also significant differences in $\mathrm{AD}$ of the G. brevipalpis populations of St Lucia 


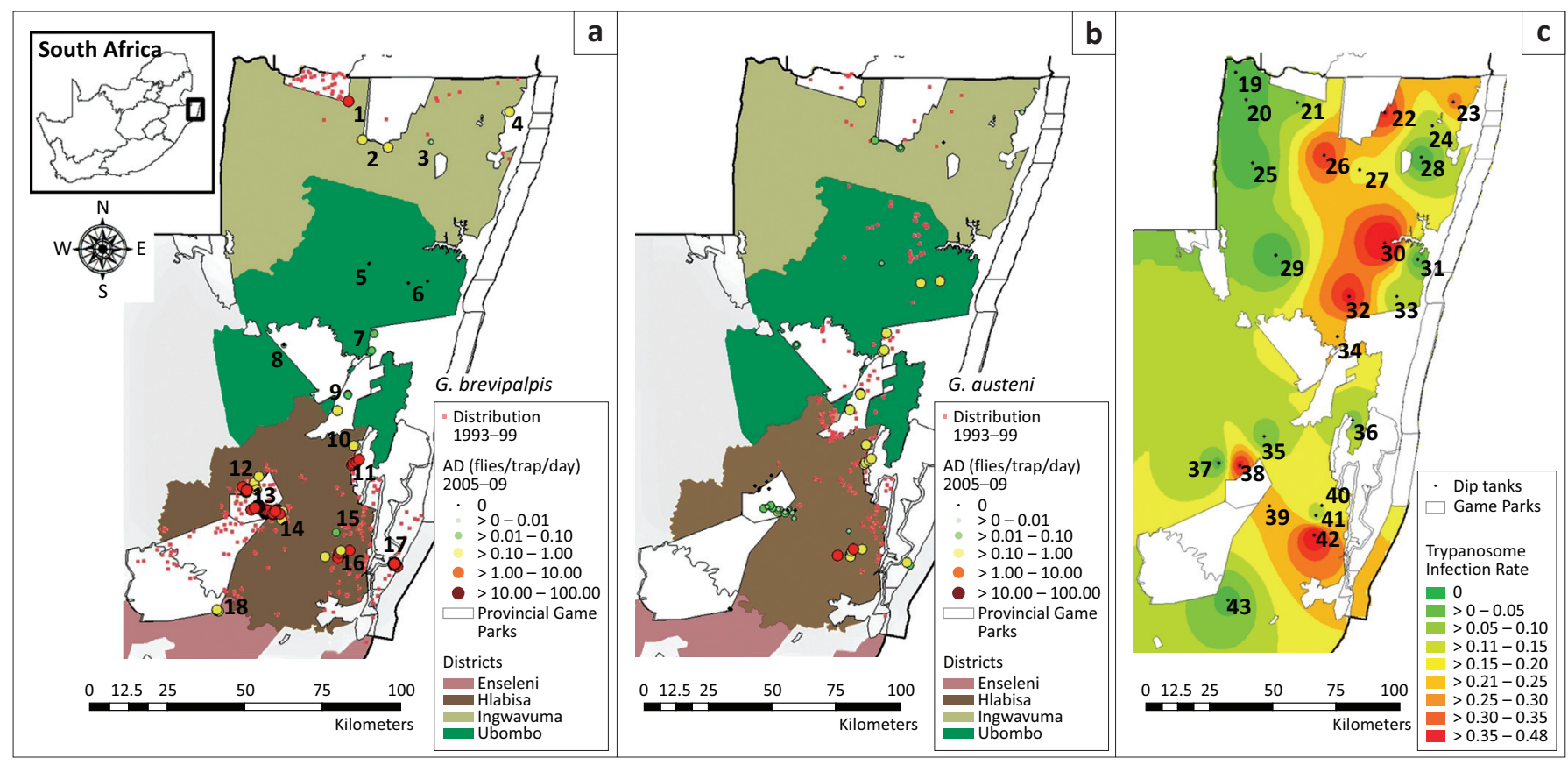

Source: Created by C.J. de Beer, ArcGIS Desktop 10.1

(a) 1: Ndumu, 2: Tembe, 3: Pelani, 4: Kosi bay, 5: Tshongwe, 6: Mbazwana, 7: Lower Mkhuze, 8: Mkhuze, 9: Phinda, 10: Kuleni, 11: False Bay Park, 12: Ekuphinidisweni, 13: Hluhluwe-iMfolozi Park, 14: Mvutshini, 15: Hlambanyathi, 16: Boomerang, 17: St Lucia, 18: Ocilwane.

(c) 19: Ekuhlehleni; 20: Khume; 21: Ndumo; 22: Manzibomvu; 23: Nhlanjwana; 24: Thengani, 25: Ntabayengwe; 26: Ngwenyambili, 27: Phelendaba; 28: Pongola; 29: Makhathini Research Station; 30: Mseleni; 31: Mpini; 32: Mkhumbikazana; 33: Mbazwana; 34: Zineshe; 35: Khipha; 36: Nibela; 37: Nthwati; 38: Ekuphindisweni; 39: Mvutshini; 40: Qakweni; 41: Mahlambanyati; 42: Boomerang; 43: Ocilwane. FIGURE 1: Apparent density of Glossina brevipalpis (a), Glossina austeni (b) and trypanosome prevalence in cattle at dip tanks (c) in north-eastern KwaZulu-Natal.

(7.25 flies/trap/day) and Kuleni (0.17 flies/trap/day). G. austeni was most abundant at Boomerang (0.78 flies/trap/ day), and this $\mathrm{AD}$ was significantly higher than that obtained in the Hluhluwe-iMfolozi Park (0.02 flies/trap/day). In the Ubombo district, the AD of G. brevipalpis at False Bay Park (1.55 flies/trap/day) was significantly higher $(p=0.044)$ than that at Phinda (0.06 flies/trap/day) and Lower Mkhuze (0.06 flies/trap/day). The AD of G. austeni was significantly higher at False Bay Park (0.60 flies/trap/day) $(p=0.002)$ in the Ubombo district as compared with the AD in Mkhuze (0.01 flies/trap/day). Finally, in the Ingwavuma district there were no significant differences in relative abundance between individual sites for both G. brevipalpis $(p=0.114)$ and G. austeni $(p=0.113)$.

\section{Trypanosome infection at dip tanks}

A total of 1034 blood samples were collected from cattle at 25 dip tanks in the tsetse-infested area and were examined microscopically for the presence of trypanosomes (Table 2). The number of cattle screened per dip tank ranged from 27 at Ekuphindisweni to 54 at Boomerang (Table 2).

Data of trypanosome prevalence (Table 2) were, as was done for the tsetse data, grouped per magisterial districts (Table 1). The results showed that trypanosome infection was widespread in north-eastern KwaZulu-Natal with positive infected cattle found at $21(84.0 \%)$ of the 25 dip tanks surveyed (Table 2; Figure 1c). Trypanosome prevalence ranged from $20 \%$ in the Ubombo district to 3\% in the Enseleni district and was not significantly different $\left(p=0.05, \chi^{2}=7.91, d f=3\right)$ between the four magisterial districts. Notwithstanding the fact that there were no significant differences between the four districts, the proportional representation of positive animals at the 25 individual dip tanks differed significantly $\left(p<0.001, \chi^{2}=173.30, d f=24\right)$. Significant differences in the proportion of positive animals per dip tank were also found within the districts of Hlabisa $\left(p<0.001, \chi^{2}=51.462, d f=6\right)$, Ingwavuma $\left(p<0.001, \chi^{2}=59.078, d f=9\right)$ and Ubombo $\left(p<0.001, \chi^{2}=51.211, d f=6\right)$. These proportional differences in infection prevalence found between individual dip tanks seemed to be linked to the distance between the dip tank and a protected area or game reserve.

The highest trypanosome prevalence (48\%) was recorded at the Mseleni dip tank which was situated next to the northern parts of iSimangaliso Wetland Park in the Ubombo district (Table 2). Similarly, trypanosome prevalence in cattle was high at dip tanks that were close to protected areas and/or game parks (Figure 1c). Especially in the Hlabisa district, a significant positive linear regression $\left(r^{2}=0.62, p=0.04\right)$ was evident between trypanosome prevalence and the distance between the dip tank and the protected areas or game parks. The same trend was also observed for the other two districts, but it was not significant (Ingwavuma: $r^{2}=0.22, p=0.17$ and Ubombo: $r^{2}$ $=0.19, p=0.41$ ). The correlation between infection prevalence and distance from the game parks was further epitomised by the absence of infected animals at the two dip tanks located more than $20 \mathrm{~km}$ further from a game park (Table 2).

\section{Tsetse relative abundance and trypanosome infection prevalence}

The trypanosome prevalence in cattle, as determined with the buffy coat technique, at the 18 dip tanks was correlated with the tsetse relative abundance, as determined with 
odour-baited $\mathrm{H}$ traps. Only dip tanks that had $\mathrm{H}$ traps deployed in a $12 \mathrm{~km}$ radius were selected for the regression analyses (Table 2). No linear correlation could be found between trypanosome prevalence and the relative abundance of either G. brevipalpis $\left(r^{2}=0.01, p=0.68\right)$, G. austeni $\left(r^{2}=0.05\right.$, $p=0.40)$ or the total tsetse catches $\left(r^{2}=0.04, p=0.43\right)$. However, at some of the dip tanks with high trypanosome prevalence in the cattle, for example, Mseleni (48\%) and Mkhumbikazana (37\%) in the Ubombo district, the AD for G. austeni was relatively high in the absence of G. brevipalpis (Figure 1a, b). In contrast, at the Ekuphindisweni dip tank in Hlabisa district where the screened cattle showed a similar high infection prevalence $(37 \%)$, the relative abundance of G. brevipalpis was high, in the absence of G. austeni (Figure 1a, b). The relative abundance of both G. brevipalpis and G. austeni was relatively high at the dip tank on the commercial farm Boomerang that is located to the west of and next to the southern extent of the iSimangaliso Wetland Park and where the highest trypanosome prevalence $(44 \%)$ was recorded in the Hlabisa district. These apparent discrepancies in AD of tsetse flies at the dip tanks with high trypanosome infection prevalence indicate that a number of factors, such as the tsetse and trypanosomosis monitoring regimes used (a trap placement radius of $12 \mathrm{~km}$ could be too large), may influence the outcome of such a regression.

\section{Ethical considerations}

Materials used in the study posed no health risk to researchers, and no vertebrate animals were harmed. The study was done as part of a project on National Assets (000773) at the ARCOVI in collaboration with the Food and Agriculture Organization (FAO)/International Atomic Energy Agency (IAEA) Division of Nuclear Techniques in Food and Agriculture and the Department of Technical Cooperation of the IAEA under project RAF 5069.

\section{Discussion}

Baseline data on tsetse distribution, relative abundance and speciescomposition, as well as the extent of the trypanosomosis problem, are essential for the development of an appropriate cost effective, sustainable area-wide control strategy (Leak, Ejigu \& Vreysen 2008; Shaw 2009; Vreysen 2005).

Previous surveys, using XT sticky traps, indicated that the G. brevipalpis population was restricted to two distinct bands in the north and south of the tsetse fly infested area in KwaZulu-Natal (Kappmeier Green 2002) (Figure 1a). These two bands were also more or less defined in the tsetse distribution prediction model for this species (Hendrickx et al. 2003; Kappmeier Green, Potgieter \& Vreysen 2007), except for a few patches predicted centrally. During the recent surveys, the $H$ trap sampled low numbers of G. brevipalpis in at least five sites in a central area in the tsetse-infested belt and located east of the Mkuzi Game Reserve and north of the southern previously defined distribution band (Figure 1a). Therefore, these positive trap catches could in part be used to update the prediction model of Hendrickx (Hendrickx et al. 2003) and indicate that G. brevipalpis is also present in the central and southern parts of Ubombo district, where it was previously not sampled. Whether this distribution is patchy or continuous still needs to be verified.

During the 1993-1999 surveys (Kappmeier Green 2002), G. austeni was sampled at the Hluhluwe Dam situated east of Hluhluwe-iMfolozi Park (Figure 1b). A transect study was therefore carried out along the Hluhluwe River, starting at the Hluhluwe Dam and progressing to the west into Hluhluwe-iMfolozi Park, with the aim to determine if G. austeni could be found in the park as predicted by the distribution model of Hendrickx et al. (2003). All traps along the transect sampled G. austeni, but at very low ADs (0.02 flies/trap/day) (Table 1). The presence of G. austeni along this transect also confirms the accuracy of the G. austeni distribution prediction model (Hendrickx et al. 2003). Glossina brevipalpis was likewise trapped in the transect traps, but this was expected considering that it had previously been collected inside and outside the Hluhluwe-iMfolozi Park (Kappmeier Green 2002). Taken into account that G. austeni is primarily restricted to and does not disperse far from dense vegetation (Esterhuizen 2007; Esterhuizen et al. 2005), and in view that bush clearing in the communal farming areas has increased considerably (Kappmeier et al. 1998), it is likely that game reserves and protected areas will become more important in sustaining G. austeni populations in the future.

The survey data of 1993-1999 indicate the southernmost extent of the Umfolozi River $(-28.5204,32.3123)$ to be the most southerly distribution of G. brevipalpis (Kappmeier Green 2002). Glossina austeni was not trapped south of the St Lucia estuary, where the Umfolozi River enters the lake (Kappmeier Green 2002). The tsetse prediction model of Hendrickx et al. (2003) suggested a very low probability of occurrence for G. austeni in the south of the Umfolozi River, but a much higher probability of occurrence for G. brevipalpis. During the 2005-2009 surveys, G. brevipalpis was collected at the Ocilwane dip tank which is $5 \mathrm{~km}$ south of the Umfolozi River - an area which had not previously been surveyed (Figure 1a). The presence of G. brevipalpis at this site also corresponds to what was predicted by Hendrickx et al. (2003), so that the predictions were confirmed at this site. The results of the recent surveys also indicate that the most southern limit of G. brevipalpis, and the factors that will determine this in the area, remain undefined. Available data indicate that the southern limit for G. austeni seems to be defined as the Umfolozi River, as was previously assumed (Kappmeier Green 2002). Similarly, the most western extent of the distribution of each species needs to be verified. Available trap catches indicate that the most western distribution limit of G. austeni was -28.10357, 32.08377 (in Hluhluwe-iMfolozi Park), whereas G. brevipalpis was collected much further west at $-28.04500,32.03900$, that is, west of Ocilwane (Figure 1a, b).

The trap catches have consequently been used to update the tsetse distribution prediction models for both G. brevipalpis and G. austeni (Hendrickx 2007). Since only data up to 2009 
are presented, ongoing and future surveys will have to be processed and incorporated into these distribution maps and models. The available trap data have partly validated the prediction model, emphasising the fact that such models can be valuable tools for the planning of tsetse and trypanosomosis intervention practices and their value should not be underestimated. Furthermore, the new distribution data will need to be taken into consideration in the suggested tsetse control strategy proposed by Kappmeier Green et al. (2007), which needs to be modified accordingly.

Trypanosome infections in cattle were recorded at 21 of the 25 dip tanks which clearly showed that the disease was still abundant and highly prevalent in north-eastern KwaZuluNatal at the time of the trypanosomosis survey (Figure 1c). A potential shortcoming of the trypanosome survey may have been that infections were not identified to species level. It was, however, previously indicated that $T$. congolense is the dominant species in the area (Mamabolo et al. 2009; Motloang et al. 2012; Van den Bossche et al. 2006).

The data on the spatial distribution of the trypanosome infection in north-eastern KwaZulu-Natal indicated that the disease was widespread in cattle, that is, from areas close to the Mozambique border in the north to a dip tank close to the Umfolozi River in the south, covering the entire length of the tsetse-infested area of north-eastern KwaZulu-Natal (Figure 1c). In general, higher infection rates were found in dip tanks located near game reserves and protected natural areas (Figure 1c), an observation also made by Van den Bossche et al. (2006) and Ntantiso et al. (2014) for dip tanks near the Hluhluwe-iMfolozi Park. This game-livestock-tsetse interface poses a high risk for cattle getting infected not only for the Hluhluwe-iMfolozi Park (Ntantiso et al. 2014), but possibly throughout north-eastern KwaZulu-Natal.

In 1994, the highest prevalence of trypanosomosis was recorded in the Ubombo district (Kappmeier et al. 1998). Although in the present study the dip tank with most of the cattle infected (Mseleni 48\%) was found in this district, the trypanosome prevalence was not significantly different from that obtained in the Ingwavuma and Hlabisa districts confirming that trypanosomosis remains a problem throughout the whole area.

The absence of a significant linear correlation between trypanosome prevalence and the relative abundance of tsetse flies in north-eastern KwaZulu-Natal may partly be attributed to the coexistence of the two tsetse species, each with a different vectorial capacity and/or competence. Previous studies indicated that the vector competence of G. austeni for $T$. congolense, the most abundant Trypanosoma species in north-eastern KwaZulu-Natal, was significantly higher than that of G. brevipalpis (Motloang et al. 2012). Our data seem to corroborate this greater vector competence of $G$. austeni in view of the relative high trypanosome prevalence recorded in cattle at the Mseleni dip tank where only G. austeni flies were sampled (Mbazwana $\mathrm{AD}=0.15$ flies $/$ trap $/$ day). However, cattle at the Ekuphindisweni dip tank showed a similar high trypanosome prevalence, but G. austeni was not sampled in the traps; only G. brevipalpis was trapped in relatively high numbers (Ekuphindisweni $\mathrm{AD}=1.59$ flies / trap/day) indicating that G. brevipalpis was most likely responsible for transmission in this area. In general, high ADs of G. brevipalpis in the vicinity of dip tanks resulted in trypanosome infection rates that were as high as those found at dip tanks where G. austeni was present but at low ADs. Hendrickx et al. (2003) also noted that low G. austeni densities coincide with areas of higher trypanosomosis prevalence in the northern communal areas. However, the very high ADs of G. brevipalpis (on average 12.6 times higher than that of G. austeni) and the much lower trap catches of G. austeni might be an artefact resulting from the intrinsic biases of the trapping system. It is known that G. austeni responds poorly to traps (Kappmeier 2000), and it is not attracted to any of the artificial odours (Kappmeier \& Nevill 1999a; Kappmeier Green 2002) used to bait traps. Essentially, mark-releaserecapture studies will be needed to confirm the low efficacy of the sampling tool used for G. austeni.

If the relative abundance of G. breviplapis is indeed a reflection of actual population densities, it can be hypothesised that the high trypanosome infection prevalence in certain areas might be the result of the greater densities of $G$. brevipalpis despite their lower vector competence. The relative low vector competence of G. brevipalpis previously found in South Africa has probably resulted in an underestimation of the importance of G. brevipalpis in the epidemiology of nagana in north-eastern KwaZulu-Natal. Vector competence studies in the laboratory have shown that the susceptibility of G. brevipalpis for T. congolensis can be as high as $12.3 \%$ (Moloo, Okumu \& Kuria 1998). In Uganda, it was shown that the infection rates for T. congolensis in G. brevipalpis collected in field could be 2.6\% (Harley 1967a, 1967b; Moloo, Kutuza \& Boreham 1980). In addition, trypanosome infection rates in tsetse flies are not constant and can change over time and between populations. In Uganda, infection rates varied considerably with the different seasons and with the age of the G. brevipalpis population (Harley 1966, 1967a, 1967b).

Both G. brevipalpis and G. austeni will readily feed on cattle (Clausen et al. 1998; Moloo 1993) and can therefore play a role in the transmission of trypanosomosis in KwaZulu-Natal. Similar average trypanosome infection rates in the three northerly districts seem to support this hypothesis even though the relative abundance and distribution of G. austeni and G. brevipalpis were clearly different.

\section{Conclusion}

The dynamics of tsetse populations can fluctuate in space and time and need to be monitored regularly for the development and implementation of an effective control strategy. Differences in fly density, distribution and ecology imply that different control strategies may be needed for the control of both these species in the nagana-infected area. The role that game parks and other protected areas may play in 
sustaining tsetse populations, as well as the circulation of trypanosomes in game animals, and the potential dispersal of both the vector and pathogen from these areas need further investigation. Furthermore, it will be essential that any strategy that aims at finding a sustainable solution to the nagana problem in north-eastern KwaZulu-Natal needs to target both tsetse fly species.

\section{Acknowledgements}

The authors thank the Department of Science and Technology and the Joint FAO/IAEA Division of Nuclear Techniques in Food and Agriculture for financial support. Also, the staff of the Parasites Vectors and Vector-borne Diseases Programme of ARC-OVI and the staff of the KwaZulu-Natal Tsetse Research Station (ZTRS) are thanked for their assistance. We thank Dr Ben Mans for constructive comments on earlier drafts of this manuscript.

\section{Competing interests}

The authors declare that they have no financial or personal relationships which may have inappropriately influenced them in writing this article.

\section{Authors' contributions}

A.A.L., K.K.G, J.E. and L.N. conceptualised and designed the study. The acquisition of data was done by C.J.d.B., D.G.d.K., J.N., R.P., K.K.G, M.J.B.V. and J.E. C.J.d.B., G.J.V., M.J.B.V., and A.A.L contributed to the analysis, interpretation of data and writing of the manuscript. All authors read and approved the final version of the manuscript.

\section{References}

Bagnall, R.J., 1993, 'Trypanosomosis in Zululand', Proceedings of the 24th Meeting of the SARCCUS Standing Committee for Animal Health, Mbabane, Swaziland, pp. 41-49.

Bagnall, R.J., 1994, 'Country report - Republic of South Africa', Prepared for a Seminar on Tsetse and Trypanosomosis Control, Nairobi, December 1994.

Bruce, D., 1895, Preliminary report of the tsetse fly disease or nagana in Zululand, Bennett \& Davis, Durban.

Cecchi, G., Paone, M., Argilés Herrero, R., Vreysen, M.J.B. \& Mattioli, R.C., 2015, 'Developing a continental Atlas of the distribution and trypanosomal infection of tsetse flies (Glossina species)', Parasites \& Vectors 8, 284. http://dx.doi. org/10.1186/s13071-015-0898-y

Cecchi, G., Paone, M., Feldmann, U., Vreysen, M.J.B., Diall, O. \& Mattioli, R.C., 2014 'Assembling a geospatial database of tsetse-transmitted animal trypanosomosis 'Assembling a geospatial database of tsetse-transmitted animal trypanosomosis
for Africa', Parasites \& Vectors 7, 39. http://dx.doi.org/10.1186/1756-3305-7-39

Clausen, P.H., Adeyemi, I., Bauer, B., Breloeer, M., Salchow, F. \&. Staak, C., 1998, 'Host preferences of tsetse (Diptera: Glossinidae) based on blood meal identifications', Medical and Veterinary Entomology 12, 169-180. http://dx.doi.org/10.1046 Medical and Veterinary Ento

De Waal, D.T., Capter, R.C., Matthee, O. \& Bagnall, R.J., 1998, 'Importance of antigendetection ELISA in monitoring and implementing control strategies for trypanosome infection in Kwazulu-Natal', in S. Morizaria, R. Masake, J. Rowlands \& T. Musoke (eds.), Antigen ELISAa for Trypanosomomes. Evaluation of the Performance. Proceedings of a workshop held at International Livestock Research Institute, Nairobi, Kenya, 9-11 December, p. 135.

Du Toit, R., 1954, 'Trypanosomiasis in Zululand and the control of tsetse flies by chemical means', Onderstepoort Journal of Veterinary Research 26, 317-387.

Emslie, F.R., 2005, 'A field evaluation of three trypanosomosis control strategies, in Kwazulu-Natal, South Africa', MSc thesis, Department of Production Anima Studies, University of Pretoria.

ESRI, 2011, ArcGIS desktop: Release 10, Environmental Systems Research Institute, Redlands, CA.

Esterhuizen, J., 2007, 'Bionomics and control of Glossina austeni and G. brevipalpis (Diptera: Glossinidae) in South Africa', PhD thesis, Department of Tropical Veterinary Diseases, University of Pretoria.
Esterhuizen, J., Kappmeier Green, K., Marcotty, T. \& Van den Bossche, P., 2005, 'Abundance and distribution of the tsetse flies, Glossina austeni and G. brevipalpis, in different habitats in South Africa', Medical and Veterinary Entomology 19(4), in different habitats in South Africa', Medical and Veterinary Ento
367-371. http://dx.doi.org/10.1111/j.1365-2915.2005.00582.x

Fuller, C., 1923, Tsetse in Transvaal and surrounding territories: An historical review, Entomology Memoir, no.1, Government printer, Department of Agriculture, Union of South Africa, Pretoria.

Gillingwater, K., Mamabolo, M.V. \& Majiwa, P.A.O., 2010, 'Prevalence of mixed Trypanosoma congolense infections in livestock and tsetse in KwaZulu-Natal, South Africa', Journal of the South African Veterinary Association 81(4), 219-223. South Africa, Journal of the South African
$\mathrm{htt}: / / \mathrm{dx} . \mathrm{doi} . \mathrm{org} / 10.4102 / \mathrm{jsava.v81i4.151}$

GraphPad Instat version 3.00 for Windows 95/NT 2003, GraphPad Software, San Diego, CA, USA, viewed 29 January 2016, from http://www.graphpad.com/ manuals/Instat3/InStat3.pdf

Hall, R.D. \& Fischer, F.J., 1984, 'Cattle ear tags containing Amitraz and permethrin for the control of face flies and horn flies on pastured herds', Journal of Agricultural Entomology 1(3), 282-286.

Harley, J.M.B., 1966, 'Seasonal and diurnal variations in physiological age and trypanosome infection prevalence of females of Glossina pallidipes Aust. G. palpalis fuscipes Newst. and G. brevipalpis Newst', Bulletin of Entomological Research 56(4), 595-614. http://dx.doi.org/10.1017/S0007485300056613

Harley, J.M.B., 1967a, 'Studies on age and trypanosome infection prevalence in females of Glossina pallidipes Aust., G. palpalis fuscipes Newst. and G. brevipalpis Newst. in Uganda', Bulletin of Entomological Research 57(1), 23-37. http://dx.doi. Newst. in Uganda', Bulletin of Entom
org/10.1017/S0007485300052676

Harley, J.M.B., 1967b, 'Further studies on age and trypanosome infection prevalence in Glossina pallidipes Aust., G. palpalis fuscipes Newst. and G. brevipalpis Newst. in Uganda', Bulletin of Entomological Research 57(3), 459-477. http://dx.doi. in Uganda', Bulletin of Entomologica
org/10.1017/S0007485300050203

Harris, R.H.T.P., 1932, 'Some facts and figures regarding the attempted control of Glossina pallidipes in Zululand', South African Journal of Science 29, 495-507.

Hendrickx, G., 2002, 'Tsetse presence-absence prediction model for Glossina austeni and Glossina brevipalpis in KwaZulu-Natal - South Africa', Consultant report prepared by Agriculture and Veterinary Intelligence and Analysis (AVIA-GIS) to the International Atomic Energy Agency, IAEA, Vienna.

Hendrickx, G., 2007, 'Tsetse in KwaZulu-Natal - An update', Consultant report prepared by Agriculture and Veterinary Intelligence and Analysis (AVIA-GIS) to the International Atomic Energy Agency, IAEA, Vienna.

Hendrickx, G., Nevill, E.M., Biesemans, J., Kappmeier Green, K., Van Camp, N. \& Williams, R., 2003, 'The use of geostatistics and remote sensing to optimise tsetse field survey results. The example of KwaZulu-Natal', Newsletter on Integrated Control of Pathogenic Trypanosomes and their Vectors 7, 26-29.

Kappmeier, K., 2000, 'A newly developed odour-baited " $\mathrm{H}$ trap" for the live collection of Glossina brevipalpis and Glossina austeni (Diptera: Glossinidae) in South Africa', Onderstepoort Journal of Veterinary Research 67, 15-26.

Kappmeier K. \& Nevill, E.M., 1999a, 'Evaluation of conventional odour attractants for Glossina brevipalpis and G. austeni (Diptera: Glossinidae) in South Africa', Onderstepoort Journal of Veterinary Research 66, 307-316.

Kappmeier, K. \& Nevill, E.M., 1999b, 'Evaluation of a proposed odour-baited target to control the tsetse flies Glossina brevipalpis and Glossina austeni (Diptera: Glossinidae) in South Africa', Onderstepoort Journal of Veterinary Research 66, 327-332.

Kappmeier, K., Nevill, E.M. \& Bagnall, R.J., 1998, 'Review of tsetse flies and trypanosomosis in South Africa', Onderstepoort Journal of Veterinary Research 65, 195-203.

Kappmeier Green, K., 2002, 'Strategy for monitoring and sustainable integrated control or eradication of Glossina brevipalpis and G. austeni (Diptera: Glossinidae) in South Africa', PhD thesis, Department of Veterinary Tropical Diseases, University of Pretoria.

Kappmeier Green, K., Potgieter, F.T. \& Vreysen, M.J.B., 2007, 'A strategy for an areawide control campaign with an SITcomponent to establish a tsetse-free South Africa', in M.J.B. Vreysen, A.S. Robinson \& J. Hendrichs (eds.), Area-wide control of insect pests: From research to field implementation, pp. 308-323, Springer, insect pests: From research to field implementation, p
Vienna. http://dx.doi.org/10.1007/978-1-4020-6059-5_29

Kappmeier Green, K. \& Venter, G.J., 2007, 'Evaluation and improvement of sticky traps as a monitoring tool for Glossina austeni and G. brevipalpis (Diptera: Glossinidae) in north eastern KwaZulu-Natal, South Africa', Bulletin of Entomological Research $97,545-553$.

Klassen, W., 2005, 'Area-wide integrated pest management and the sterile insect technique', in V.A., Dyck, J. Hendrichs \& A.S. Robinson (eds.), Sterile insect technique. Principles and practice in area-wide integrated pest management, technique. Principles and practice in area-wide integrated pest management, pp. 39-68, Springe $4020-4051-2 \_2$

Leak, S.G.A., Ejigu, D. \& Vreysen, M.J.B. 2008, Collection of entomological baseline data for tsetse area-wide integrated pest management programmes: FAO anima production and health guidelines, Food and Agriculture Organization of the United Nations, Rome, Italy.

Mamabolo, M.V., Ntantiso, L., Latif, A. \& Majiwa, P.A.O., 2009, 'Natural infection of cattle and tsetse flies in South Africa with two genotypic groups of Tryponosoma congolense', Parasitology 136, 425-431. http://dx.doi.org/10.1017/ S0031182009005587

Moloo, S.K., 1993, 'The distribution of Glossina species in Africa and their natural hosts', International Journal of Tropical Insect Science 14, 511-527. http://dx.doi. org/10.1017/S1742758400014211 
Moloo, S.K., Kutuza, S.B. \& Boreham, P.F.L., 1980, 'Studies on Glossina pallidipes, G. fuscipes fuscipes and G. brevipalpis in terms of the epidemiology and epizootiology of trypanosomiases in south-eastern Uganda', Annals of Tropical Medicine and Parasitology 74, 219-237. http://dx.doi.org/10.1080/00034983.1980.11687333

Moloo, S.K., Okumu, I.O. \& Kuria, N.M., 1998, 'Comparative susceptibility of Glossina longipennis and G. brevipalpis to pathogenic species of Trypanosoma', Medical and Veterinary Entomology 12, 211-214. http://dx.doi.org/10.1046/j.13652915.1998.00095.x

Motloang, M.Y., Masumu, J., Mans, B., Van den Bossche, P. \& Latif, A.A., 2012, 'Vector competence of Glossina austeni and Glossina brevipalpis for Trypanosoma congolense in KwaZulu-Natal, South Africa', Onderstepoort Journal of Veterinary Research 79(1), 6. http://dx.doi.org/10.4102/ojvr.v79i1.353

Motloang, M.Y., Masumu, J., Mans, B.J. \& Latif, A.A., 2014, 'Virulence of Trypanosoma congolense strains isolated from cattle and African buffaloes (Syncerus caffer) in KwaZulu-Natal, South Africa', Onderstepoort Journal of Veterinary Research 81(1) Art. \#679, 7 pages. http://dx.doi.org/10.4102/ojvr.v81i1.679

Ntantiso, L., De Beer, C., Marcotty, T. \& Latif, A.A., 2014, 'Bovine trypanosomosis prevalence at the edge of Hluhluwe iMfolozi Park, KwaZulu-Natal, South Africa' Onderstepoort Journal of Veterinary Research 81(1), Art. \#762, 8 pages. http:// dx.doi.org/10.4102/ojvr.v81i1.762

Paris, J., Murray, M. \& McOdimba, F., 1982, 'A comparative evaluation of the parasitological techniques currently available for the diagnosis of African trypanosomiasis in cattle', Acta Tropica 39, 307-316.
Shaw, A.P.M., 2009, 'Assessing the economics of animal trypanosomosis in Africa History and current perspectives', Onderstepoort Journal of Veterinary Research 76(1), 27-32. http://dx.doi.org/10.4102/ojvr.v76i1.57

Steverding, D., 2008, 'The history of African trypanosomiasis', Parasites and Vectors 1, 3, viewed 29 January, 2016 from http://www.parasitesandvectors.com/ content $/ 1 / 1 / 3$

Taioe, M.O., 2014, 'Molecular detection, genetic and phylogenetic analysis of trypanosome species in uMkhanyakude district of KwaZulu-Natal province, South Africa', MSc thesis, Department of Zoology and Entomology, University of the Free State.

Van den Bossche, P., Esterhuizen, J., Nkuna, R., Matjila, T., Penzhorn, B., Geerts, S., et al., 2006, 'An update of bovine trypanosomosis situation at the edge of Hluhluwe iMfolozi Park, KwaZulu-Natal Province, South Africa', Onderstepoort Journal of Veterinary Research 73, 77-79. http://dx.doi.org/10.4102/ojvr. v73i1.172

Vreysen, M., Robinson, A.S. \& Hendrichs J., 2007, Area wide control of insect pests From research to field implementation, Springer, Dordrecht, The Netherlands. http://dx.doi.org/10.1007/978-1-4020-6059-5

Vreysen, M.J.B., 2005, 'Monitoring sterile and wild insects in area-wide integrated pest management programmes', in V.A. Dyck, J. Hendrichs \& A.S. Robinson (eds.) Sterile insect technique: Principles and practice in area-wide integrated pest management, 1st edn., pp. 325-361, Springer, Dordrecht, The Netherlands. http://dx.doi.org/10.1007/1-4020-4051-2_12 